\title{
AMELOBLASTOMA MULTICÍSTICO: RELATO DE CASO CLÍNICO
}

Felipe Bueno Rosetti BERNABÉ, Diego PEREIRA, Jean Carlos GERHARDT, Delson João da COSTA

Os ameloblastomas são neoplasias odontogênicas benignas de origem epitelial com comportamento localmente agressivo. Acometem predominantemente a mandíbula e podem atingir proporções variadas de acordo com o tempo de evolução. Manifestam-se geralmente entre a terceira e quinta décadas de vida. Paciente E.R., sexo masculino, 30 anos, foi encaminhado ao serviço de Cirurgia e Traumatologia Buco-maxilo-faciais da Universidade Federal do Paraná com aumento de volume em região de corpo e ângulo mandibular do lado esquerdo. Na anamnese, paciente relatou remoção de terceiro molar inferior esquerdo há um ano. Ao exame clínico, observou-se aumento de volume de consistência endurecida do lado esquerdo da mandíbula. Ao exame de imagens, observou-se uma lesão multiloculada radiolúcida de aproximadamente $6 \mathrm{~cm}$ em ramo, ângulo e corpo mandibular. Realizaram-se então, punção exploratória e biópsia incisional, confirmando a hipótese diagnóstica de ameloblastoma. Devido à extensão da lesão e seu poder recidivante, optou-se pela ressecção parcial de mandíbula e reconstrução com placa de titânio. A peça removida foi enviada para análise anatomopatológica, confirmando o diagnóstico. Cinco meses após a cirurgia, houve fratura na placa de reconstrução e o paciente foi submetido à nova cirurgia para troca da placa. Após um ano, o paciente encontra-se sem alterações estéticas e funcionais. 